\title{
UM FABULOSO REDESCOBRIMENTO. (Para justificação da existência de música erudita no período colonial brasileiro).
}

\author{
FRANCISCO CURT LANGE
}

Presidente do Instituto Interamericano de Musicologia

(Montevidéo) .

Transcorreram 32 anos desde que me coube descobrir, em Minas Gerais, a existência de música colonial erudita de elevada qualidade. $E$ bem sabido a resistência que provocou este fato na crítica musical carioca, que ultrapassou nas suas arremetidas não poucas vezes os limites da ética profissional para me dificultar, com todos os meios possíveis, a continuação dos meus trabalhos de pesquisa e restauração de obras que foram incorporadas, já faz anos, ao repertório coral-sinfônico de conjuntos de responsabilidade e fama. Por razões bem diversas, mas no meio do maior respeito e amizade, tambem um setor da historiografia nacional, achando que correspondia aos religiosos desempenhar nas igrejas atividades musicais, não podia, de forma alguma, aceitar que estes misteres se desenvolvessem com inteira independência, exercidos por profissionais constituidos em corporações que agiam debaixo da égide da Irmandade de Santa Cecília, poderosa instituição fundada em Lisboa em 1603 e transplantada, como inúmeras tradições lusitanas, para o Brasil. Para o historiador, quem mexia com música eram os Padres e os Monges. Ainda mais resistência, inclusive em Minas Gerais, encontrou a minha afirmação de terem sido mulatos, durante dois ou mais séculos, os que se dedicavam com virtual exclusividade "racial", muito especialmente em Minas, ao exercício profissional da música erudita, na sua reconhecida condição de professores da arte da música. Salomão de Vasconcellos e Eduardo Frieiro pertenciam ao grupo que não acreditava nas minhas asserções, até serem vencidos por documentação contundente.

As corporações de músicos trabalhavam independentemente de qualquer sujeição aos foros do clero e como não foram admitidos às Ordens de Regulares, os serviços de música eram contratados, por um 
lado, pelo clero secular da Ordem de São Pedro, e por outro, pelas Mesas das numerosas Irmandades. Ainda hoje continua subsistindo o grave erro de imaginar que eu tenha encontrado toda a música antiga do período áureo, nas Matrizes, Igrejas e Capelas, o que constitui fenomenal erro na apreciação dos meus esforços em torno da música religiosa daquele tempo. Os músicos mineiros, tendo por cabeça de cada grupo um regente, que por sua vez era cantor ou instrumentista (partícipe do programa a ser executado), iam da sua sede, fazer prévios ensaios nela ou na igreja, com os seus papeis de música e voltavam com estes para os arquivar nas prateleiras do seu local ou na casa do mestre-regente. Nunca jamais encontrei uma só folha de música nos templos mineiros, com exeção dum caso, que aconteceu na Matriz do Serro, onde morreu o regente duma corporação, ficando no Coro um baú com papeis de música que não foi reclamado pelos herdeiros, por não terem podido seguir a vocação do pai. Eram mulheres. Este arquivo foi entregue por mim a Dom José Newton de Almeida Baptista, quando Arcebispo de Diamantina e incorporado por ele ao arquivo da sua Arquidiocese.

A organização musical mineira do século XVIII teve uma só variante, quando foi instituido em Mariana o primeiro Bispado, em 1748. Frei Manoel da Cruz nomeou Mestre de Capela no início das suas funções de Pastor máximo, com sujeição total ao calendário do culto eclesiástico da igreja católica romana. Recebia os seus emolumentos da Cúria. Os músicos de livre profissão cobravam, após a sua participação na festa religiosa, a quantia estipulada pelas Matrizes, o Senado da Câmara, o Teatro e as Irmandades.

Longos anos de lutas para impor a verdade, e pesadas pesquisas para esclarecer inúmeros fatos com documentação irreversivel, foram necessários para lançar suficiente luz sobre um passado que ninguem havia podido imaginar antes do meu descobrimento. A história musical brasileira pontificou durante anos a impossibilidade de ter existido música erudita ao longo do período colonial, e quando comprovei o contrário, com apresentações qualitativas de insuspeita beleza, após longo processo de restauração de muitas obras, chegou-se a afirmar que estas tinham sido adulteradas ou compostas por mim, como tendo falsificado todo um setor dum período literário e artístico do qual faltava apenas o elo da música para faze-lo completo e totalmente harmonioso. Até hoje não compreendo como a historiografia musical brasileira não refletiu que o primoroso acabamento das igrejas do Brasil colonial exigia a presença de música de idêntica qualidade.

Achada a impressionante atividade musical do período colonial mineiro, e como cúspide o florilégio de compositores de grande categoria artística, a minha maior preocupação foi dar a voz de alerta para 
se conservar os arquivos musicais, que se achavam em mãos de velhos mestres ou dos seus descendentes que desconheciam o seu valor real, deixando apodrecer as páginas amarelentas debaixo de goteiras ou entregando-as aos ratos, às baratas, ao cupim e à traça. Um processo igualmente corrosivo se originou nos Arquivos das Irmandades religiosas, tanto de brancos, como de mulatos e pretos, onde a administração dos bens por meio de inventários e a administração complexa ligada ao seu funcionamento, oferecia grandes possibilidades para reconstruir a atividade musical contratada com as respectivas corporações de músicos, frequência das festividades, número dos partícipes nas audições, aquisição, reparações e mais informação sobre os orgãos, nomes dos regentes e dos músicos. O próprio Arquivo Público Mineiro, em Belo Horizonte, até poucos anos atrás não podia aplicar com regularidade trabalhos de desinfecção nos códices, nem preparar um fichário e menos ainda estabelecer uma vigilância adequada para a conservação das suas valiosas coleções, vítimas tambem dos roedores.

Muita música vendeu-se a peso para embrulhar carne nos acougues e artigos diversos nos comércios. Em certa ocasião andei à caça de 700 kilos de papel de música vendida nesta condições em Ouro Preto. Persegui o seu rasto em Belo Horizonte, Santa Luzia, Sete Lagoas e outros pontos até acha-lo bem conservado, distribuido entre as duas corporações de música rivais de Itabirito. Depois de não ter podido regressar a Minas Gerais em quase oito anos, pela falta de meios, e apesar de duas cartas dramáticas dirigidas ao então Presidente do Estado, Dr. Juscelino Kubitschek, - que não foram respondidas soube de 27 arquivos queimados no quintal ou na rua, diante dos visinhos, porque "estavam incomodando". Muito papel de música foi sacrificado para os foguetes por ter sido este preferido pela sua boa resistência à pólvora.

Posteriormente, sempre clamando pela conservação de música antiga, houve uma lenta reação, indo aos poucos para o outro extremo. Hoje, estou seguro, ninguem vende uma folha de música sem the dar valor crescido, muitas vezes sem justificação. Quantas vezes me foram oferecidos a preço exorbitante partes instrumentais de dobrados, valsas, polkas e transcrições de fantasias de óperas, copiadas por mestres de banda do século XIX e XX. Voltando à queima de música, vale a pena citar um caso flagrante. Aconteceu em Ouro Preto, no segundo ano das minhas pesquisas, iniciadas em 1944. Fui várias vezes à antiga capital, formulando perguntas por antigos arquivos de música. Andei por várias casas, moradias de instrumentistas ou mestres de cantoria, onde me mostraram papeis todos pertencentes às últimas décadas do século XIX, sem interesse nenhum para os meus objetivos. Certamente, com a mudança da capital em 1897, tambem transladaram-se os principais mestres daquela época, pois não se pudendo 
sustentar só com a música, foram funcionários públicos, assim, por exemplo, Justino da Conceição, que morava na Floresta, bairro de Belo Horizonte, último desta estirpe de músicos bem preparados e cuidadosos no manejo dos papeis e na cópia das partes. Estava vendendo o seu arquivo e o do seu cunhado, já falecido, aos inexpertos padres da zona da Mata que jamais poderiam ter tirado proveito das obras por carecer do instrumental acompanhante do período homófono mineiro. Empregado do Correio, Justino foi transferido no ano da fundação da nova capital.

Evidentemente, Ouro Preto não conservava música do período que tanto suscitou o meu interesse. Numa visita, um amigo me indicou, como último recurso, a Cândido Simplício Marçal, servente da Escola de Farmácia. Encaminhei-me para o lugar e encontrei um moreno reservado, dotado, porem, de grande sinceridade. Explicou-me que de fato, era possuidor de música que ele salvou acidentalmente duma fogueira que a viuva do mestre Leão fez na rua, diante da sua casa, com velha música. Vindo o fogo de passagem para a Igreja de São Francisco de Paula dos Mínimos, na qual servia de Sacristão, aproximou-se por mera curiosidade e descubrindo que eram papeis de música, formando ele mesmo parte da cantoria da sua igreja, procurou um balde, encheu-o várias vezes de água até apagar o fogo da melhor forma possivel, retirando logo das cinzas o que ainda poderia servir. Levou esses materiais para a espaçosa Sacristia da Igreja e, sobre uma mesa imensa, extendeu os papeis molhados, para os poder secar aos poucos. Lá estavam, fazia já uma semana quando eu entrei em contato com o Cândido Simplício, mineiro calado, simples e como a maioria, bondoso e hospitaleiro. Introduzindo-me na Sacristia, numa hora fixada previamente, mostrou-me os papeis por ele salvados na última hora, quando as chamas já tinham quase concluido o seu festim.

Surpreendido, me encontrei, pela primeira vez, com cs nomes de Marcos Coelho Netto, Francisco Gomes da Rocha $\mathrm{c}$ com materiais de autores anônimos. Abriu-se desta maneira o panorama, em forma mais completa, dum passado musical que ainda era misterioso para mim. Semanas mais tarde, já impossibilitado de realizar cópias destes materiais (não existiam durante a segunda guerra mundial placas fotográficas em quantidades suficientes), Cândido Simplício Marçal tomou a decisão de me obsequiar espontâneamente com os papeis postos por ele a salvo, facilitando-me uma consideravel aproximação dos problemas candentes da atividade musical mineira que foi para mim um grande mistério que ainda procurava explicar-me como provindo de Portugal e exercida por portugueses.

Se durante muitos anos lutei sosinho, enfrentado a difamações e dúvidas, de uns anos para cá, contei com a valiosa cooperação de his- 
toriadores de renome, de músicos capazes e de espírito objetivo, que souberam dar a devida importância aos acontecimentos musicais durante o período barroco mineiro, ajudando-me com recopilações para mim desconhecidas ou trazendo, por iniciativa própria, complementações valiosas, extraidas tanto dos arquivos de Portugal como dos do Brasil e preenchendo desta forma lacunas que eu não consegui achar nas minhas pesquisas. Tais o Dr. Ivo Porto de Menezes e o Dr. Geraldo Dutra de Moraes, para nomear os que mais de perto estiveram do meu ideário. Posso dizer, sem exagero, que a reunião de valioso material no Museu da Arquidiocese de Mariana pela Sua Eminência o Arcebispo Dom Oscar de Oliveira; a decisão do antigo Arcebispo de Diamantina, Dom José Newton de Almeida Baptista, de ceder da sede do Arcebispado um terreno para formar uma praçinha dando-lhe o nome de José Joaquim Emerico Lobo de Mesquita; a posterior denominação do Conservatório da cidade com o nome deste grande compositor, assim como a reunião de documentação valiosa pelo atual Arcebispo Dom Geraldo de Proença Sigaud; o descobrimento do arquivo musical no "Pão dos Pobres" na mesma povoação; a realização de importantíssima obra musicológica pelo Padre Jaime Diniz, não só no Recife mas tambem na Bahia; o descobrimento, na Coleção Lamego, da Faculdade de Filosofia, Ciências e Letras da Universidade de São Paulo, por Régis Duprat, do Recitativo e Aria composto por autor anônimo em Salvador, e restaurado por ele, a quem entreguei logo todo o setor paulistano para uma sistemática exploração que deu magníficos resultados; tudo foi consequência das minhas insistentes advertências para se conservar documentos musicais antigos. Repercutindo em mentalidades esclarecidas, foi possivel salvar um ínfimo resto do que foi outrora um incrivel repositório de obras musicais. Incitei-os para prosseguir o que eu tinha começado com inúmeras dificuldades, percorrendo primeiro pela estrada de ferro e logo em jeep, - cedido pelo ilustre Vice-Governador do Estado e posteriormente Ministro da Educação e Cultura, Dr. Clovis Salgado, ainda sem as estradas que hoje são um luxo em Minas - as paragens mineiras em perigosas viagens, com várias quedas nos mataburros e levando sobressalentes de gasolina para abastecimento em lugares ermos, continuadamente expostos a nos queimar (sempre viagei com a minha esposa), numa possivel batida com outro carro ou numa derrapagem imprevista .

Hoje, a musicologia universal considera que a existência duma intensíssima atividade musical na Capitania Geral das Minas Gerais e a presença de compositores de não imaginado vulto - movimento que se achava exclusivamente em mãos de mulatos - representa 0 maior descobrimento feito nos últimos 180 anos, suscitando ao mesmo tempo motivo bastante para aprofundar a formação sociológica neste Estado, meltingpot violento de diversas raças. Apesar do reco- 
nhecimento no exterior dos valores mineiros, no Brasil estamos ainda longe de compreender no seu verdadeiro alcance esta afirmação, na qual tenho contribuido proferindo, por cima, mais de 2.000 conferências e dando cursos de extensão em Universidades, Academias, Conservatórios, rádio e emissoras e outras instituições, dedicando-me à gênese da música mineira em 23 paises europeus e em quase todo o hemisfério americano. Organizei concertos das obras restauradas com conjuntos de notória importância que tiveram em muitos casos uma repercussão apoteótica, e para cantores, instrumentistas, coro e regente as mais elevadas satisfações, culminando sempre num verdadeiro deslumbramento com as obras dos egrégios mulatos. Devo citar as interpretações nas Universidades Nacionais de Tucumán, Mendoza, Buenos Aires, San Juan e na Catedral da capital argentina, em Montevideo, Santiago de Chile, nos Estados Unidos (Nova Iorque, Filadélfia e Washington, D. C., e nas Universidades de Texas, Tulane e Indiana); na Alemanha (Gelsenkirchen, Karlsruhe, no Senado da Câmara da Livre Cidade Hanseática de Bremen, na sua famosa sala renascentista, e na Catedral de Freiburg); em Viena, Zurique e Pamplona (Espanha) com o seu coro mundialmente famoso; em Lucca durante os seus festivais internacionais, em Roma na belíssima Igreja de Santa Agnese in Agone, na Piazza Navona, ao lado da Embaixada do Brasil, no México e no Senegal. Como aliados de inestimavel valor cito novamente o Dr. Clovis Salgado, o maestro Olivier Toni como o mais pujante e capacitado intérprete dos mineiros no Brasil, numerosos regentes brasileiros, dentro estes o maestro Pablo Komlos, diretor da orquestra Sinfônica Estadual de Porto Alegre, e o argentino Rodolfo Kubik, autoridade indiscutivel, que teve a iniciativa de fazer estréia destas obras, reiteradas vezes, em Buenos Aires, e pela primeira vez, no dia da Inconfidência, em Ouro Preto, quando o Governo se translada, uma vez por ano, para a antiga Capital.

Nas minhas exposições sobre o fascinante tema, acompanhando-as com diapositivos e fitas magnéticas, nas Universidades européias e norte-americanas, onde se ignorava até a posição geográfica de Minas Gerais, a uma hora e meia de exposição verbal, seguia-se idêntico lapso de tempo num cordial colóquio sobre inúmeros detalhes que o assunto suscitava e a música revelava. Muitos dos concertos tiveram de ser repetidos, como no México, em Pamplona, em Roma e em Lucca, onde o auditório que enchia a espaçosa catedral, pediu a repetição do Credo de Parreiras Neves. Não satisfeito, como conta o Professor Toni, seguiu o público aos cantores e instrumentistas paulistanos para lhes pedir, já na Sacristia, com os músicos guardando os seus instrumentos, mais uma repetição desta obra. Conta hoje o reconhecimento dos compositores de Minas Gerais com uma pequena, mas substanciosa legião de aliados que deram a sua capacidade, o seu interesse e as suas 
convições em favor deste núcleo, já famoso, dos músicos de cor que jaziam inteiramente desconhecidos. Um número superior de 90 trabalhos elaborados por mim sobre este período, deu oportunidade para os distribuir entre individualidades e centros musicológicos do mundo inteiro e se o Governo brasileiro houvesse cooperado na edição das partituras por mim restauradas, a divulgação deste glorioso período poderia ter sido muito maior .

Contudo, não está dita a última palavra sobre a música colonial brasileira, que teve o seu esplendoroso desenvolvimento tambem no Recife, na Bahia, e posteriormente, no Rio de Janeiro e em São Paulo, segundo o processo do deslocamento humano para as Minas Gerais, onde verificou-se a concentração da maior riqueza e o povoamento mais compacto na História do Brasil. Muito, ou quase tudo, se tem perdido pela indolência dos homens e a sua falta de responsabilidade histórica. Estou convencido que uma demora de mais alguns anos me teria impedido de descobrir este poderoso movimento, devido à perda total dos comprovantes documentais da música.

Foi necessário este preâmbulo para chegarmos ao relato dum fato sem precedentes, que deveria pesar definitivamente no espírito daqueles que, sem ter a suficiente capacidade de julgamento, nem preparo profissional, terão de capitular perante uma documentação impar que foi redescoberta em Evora. Trata-se dum Códice de dois grossos volumes, já citado por Ernesto Vieira no seu Dicionário Biográfico de Músicos portugueses (1900), que se achava na Biblioteca Pública de Evora e desapareceu durante anos por uma simples colocação errada nas pratileiras desta riquíssima instituição. Quem reencontrou esta preciosidade foi o ilustre cônego José Augusto Alegria, autêntico musicólogo de importante e vasta obra, que é membro correspondente do Instituto Interamericano de Musicologia, com sede em Montevideo, mas tambem amigo do mais alto apreço.

Quando se realizou em Braga, o Congresso de Estudos sobre a Arte em Portugal no século XVIII, o cônego Alegria, apresentou uma comunicação que transcrevemos na íntegra, para reservarmos um comentário adicional após um exame in situ, quando, de passagem por Espanha e caminho a Lisboa, nos desviamos da rota para um breve estágio no Paço Ducal de Vila Viçosa, onde praticamos pesquisas em 1961-62, indo logo saudar em Evora o querido cônego, que tem a sua moradia na poética Rua da Cosinha de Sua Alteza, no no 9.0 dia seguinte, após um almoço brindado pelo ilustre redescobridor, foi-me dado examinar os dois grossos volumes, aos quais atribuo, com ele, não apenas uma impor- 
tância local, senão uma transcendência que ultrapassa toda imaginação daqueles que não sabem compenetrar-se da real situação criada entre as personalidades da Metrópole e aquelas que migraram alem do Atlântico, carregadas de experiência e dispostas a transmiti-la aos que nasceram no território ultramarino. Para muitos, o Brasil foi terra erma, falto de comunicações e de interesses superiores, mole e rústico. Sem embargo, houve uma plêiade de varões ilustres que possuiam conhecimentos vastíssimos e invejáveis, juntos com uma prática superior no diário manejo da interpretação de obras eclesiásticas e profanas, não recusando em nenhum instante sacrifícios pecuniários para se munir de uma bibliografia das mais vastas para melhorar o seu conhecimento na matéria.

O que tem sido sintomático em Minas Gerais, ou seja, a ininterrupta aquisição de documentação musical teórica e prática, não foi outra coisa senão a continuação das tradições portuguesas trazidas primeiro ao Nordeste e transplantados para Minas em grau superlativo, devido à densidade dos que se dedicavam ao exercício da música. $O$ músico português pertencente ao clero, na sua maioria da Ordem de São Pedro e logo das Ordens monásticas, não trazia apenas o seu saber, adquirido nas famosas Escolas de Evora, Vila Viçosa, Elvas, Coimbra, Portoalegre e na Sé Metropolitana de Lisboa mas continuava cultivando da melhor forma possivel, percebendo o grande talento dos brasileiros natos e muito particularmente, o da crescente grei dos mulatos. Estes, por sua vez, herdaram a mesma curiosidade, a mesma inquietação para adquirir cada vez maiores conhecimentos na sua arte, mandando pedir a Lisboa tudo o que fosse necessário para nutrir melhor os seus conhecimentos práticos e teóricos. Existia uma corrente ininterrupta de ensinamentos de música e tratados por parte dos compositores mulatos, secundados com ampla visão pelo Clero superior. A tradição portuguesa não morreu no momento de abandonar a terra lusitana; continuou vivendo e se intensificando nas consciências dos que serviam à arte musical. E como Portugal foi terra aberta, considerada a mais européia, a ela afluiam obras da mais elevada expressão artística oriundas da Itália, da Áustria e Alemanha, da Holanda, Inglaterra e França.

O Recitativo e Aria, de autor anônimo, escrito na Bahia em 1759, é uma demonstração do alto nivel atingido na atividade musical da antiga capital do Brasil. Obra ocasional ou circunstancial, é comprovação do que acontecia num ambiente onde a música funcional, escrita para cada uma das numerosas ocasiões, se achava predominando, inclusive na maioria dos serviços na igreja. Coincidentemente, o primeiro volume da obra teórica que comentamos, foi posto a limpo no mesmo ano, e o segundo em 1760 , porem, é evidente que o texto foi confecionado entre os anos 20 e 30 do século XVIII, como se poderá 
saber pelas linhas que se seguem. Autor desta portentosa obra foi o Padre Caetano de Melo de Jesus, Mestre de Capela da Catedral da Bahia, e natural do mesmo Arcebispado. Como vemos, foi brasileiro nato, sem que saibamos, no momento, se foi mulato ou branco, o que certamente pouco importa neste caso.

A Bahia, a nosso ver, tem sido sempre, como capital do Brasil, tradicionalmente portuguesa, inclusive no exercício da música. Para lá foram enviados os melhores mestres de capela e para a Bahia foram transportados e eregidos os primeiros orgãos, tocados por excelentes organistas. Tudo veio da Metrópole. O mulatismo, paralelamente com o de Minas Gerais, foi evoluindo e aceitado no Recife, porque para o advento da música homófona foram necessários cantores e instrumentistas suficientes. E como o português não se prestava para estes misteres, inclinando-se decididamente para o comércio e após para o descobrimento das jazidas de Minas Gerais, a mineração e ao enriquecimento rápido, a profissão de música deixada de lado, foi rapidamente preenchida pelo mulato, o que se deu já no Recife nos tempos de Maurício de Nassau. A paixão pela habilidade musical do mulato, filho de português e de negra, destacou-se rapidamente e quando do descobrimento das minas auríferas e dos jazidas de diamantes, os músicos pisaram os calcanhares dos mineradores em procura duma melhor posição econômica, tendência generalizada no desenvolvimento da Capitania Geral.

Vamos agora transcrever na íntegra a comunicação do Reverendo Cônego José Augusto Alegria para o Congresso de Estudos sobre A Arte em Portugal no século XVIII, realizado em Braga, e terminar este artigo com alguns comentários para explicar melhor o que aconteceu neste século em matéria musical num Brasil colonial para nós ainda muito desconhecido e misterioso, povoado por personalidades que aos poucos vem surgindo das trevas do passado.

\section{UM TEÓRICO BRASILEIRO DO SECULO XVIII.}

\section{(Comunicação apresentada ao Congresso de Estudos sobre "A Arte em Portugal no Século XVIII", em Braga).}

Costumam os historiadores da música brasileira, marcar como início da sua aventura na arte dos sons, partindo do $\mathbf{P}$. José Maurício Nunes Garcia cuja vida decorre entre 1767 e 1830. Para lá do Mestre da Capela da Catedral do Rio de Janeiro, apenas se enuncia o folclore resultante, mais ou menos, da misteriosa sim- 
biose do ameríndio com o negro afrciano. A presença dum compositor da categoria do $\mathbf{P}$. José Maurício, surge na história como fruto sem raizes, o que, logo à primeira vista, pode levantar graves suspeitas de que assim tenha sido de fato. Os sintomas de maioridade que ressaltam da obra do $\mathbf{P}$. José Maurício, refletem constantes de cultura musical perfeitamente identificadas com a técnica e a estética que era cultivada na Europa e é bem sabido que a cultura, em qualquer das suas manifestações, supõe centros de irradiação que a justificam, pelo menos, nas suas estruturas teóricas.

O facto de Portugal não ter tido no século XVIII artistas que abrissem caminhos novos na evolução da arte da música, não é impeditivo que tenha tido nesse período músicos de alta qualidade ligados a estruturas escolares em condições de levarem ao Brasil uma imagem da arte musical tal como se praticava no continente europeu.

Claro que a história tem as suas leis e o seu código de honra é constituido pelos documentos.

C. eio que foi o Professor Curt Lange, que não é brasileiro nem português, quem, pela primeira vez abriu brecha nesta visão mítica da história da música do Brasil, dando a conhecer com exuberante cópia documental, a existência no vasto território brasileiro, de centros musicais de nivel surpreendente. Recordo apenas Os Compositores na Capitania Geral das Minas Gerais, trabalho publicado na Revista "Estudos Históricos" da Faculdade de Filosofia, Ciências e Letras de Marília, em 1965 e La Música en Villa Rica que saiu em separata da "Revista Musical Chilena", em 1967-68.

E na sequência da țese de Curt Lange que trago à colação a notícia de um códice manuscrito composto de dois grossos volumes cujo autor é o Padre Caetano de Melo de Jesus que foi mestre da capela da Catedral da Bahia e era natural do mesmo Arcebispado. Datado de 1759 e 1760 , pertence ao fundo dos manuscritos que se guardam na Biblioteca Pública de Evora. Apenas conheço a referência que the faz Ernesto Vieira na sua utilíssima obra que é o Dicionário Biográfico de Músicos Portugueses, publicado em 1900. Todavia, sou de parecer que Ernesto Vieira não se apercebeu do alto interesse que teria o manuscrito brasileiro que, quanto mais não fosse, refletia a imagem cultural levada pelos colonizadores portugueses para lá do Atlântico.

O título da obra é o sèguinte: Escola de Canto de Orgão. Música Praticada em Forma de Diálogo entre Discípulo e Mestre. Das quatro partes anunciadas pelo autor, apenas existem duas, ignorando se a terceira e quarta se perderam ou se não chegaram a ser escritas. Os dois'volumes foram manuscritas pela mesma mão numa caligrafia cuidada a que se juntam esquemas e resu- 
mos de vária ordem que são sinal evidente de competência e carinho no esforço dispendido.

Trata a primeira parte da música teórica ou método doutrinal que prática e teoricamente, segundo os modernos, explica aos principiantes os principais preceitos da arte; e a segunda parte explana a teoria dos intervalos, quantidade, números e proporções. Qualquer deles com perto de seiscentas páginas. Não tem cabimento, neste momento, qualquer veleidade de análise, ainda que superficial, de tão denso trabalho, o mais denso de entre todos os teóricos musicais que escreveram em lingua portuguesa. Apenas me permito chamar a atenção para o valor cultural da obra considerada como afirmação de opções pessoais do autor no campo da técnica e como expressão verdadeiramente européia.

Quanto ao primeiro aspecto, o Padre Caetano de Melo de Jesus inseriu na segunda parte do seu trabalho, a partir da página 517, um "Discurso apologético no qual se trata dos membros do diapasão ou oitava sujeita a outras tantas divisões do genero cromático, duro ou mole, quantos são os sustenidos ou bemois figurados diante da clave". Eis-nos perante um problema teórico discutivel, então, e que o autor trata com amplos conhecimentos da matéria. Não se limitando, porem, a expor uma tese e a fechar-se na torre de marfim, o Padre Caetano resolveu pedir a opinião sobre o asunto, a mestres de reconhecida competência, quer da América quer da Europa, palavras usadas pelo próprio. Os mestres chamados a depor foram, para o Brasil, o P. Inácio Ribeiro Noia, o P. Inácio Ribeiro Pimenta e o P. Antônio Nunes de Sequeira, respectivamente, mestres das Sés de Pernambuco, Olinda e Rio de Janeiro. Respondeu ainda o Arcedíago da Sé de Olinda, Manuel da Costa Rego que seria musicólogo de categoria reconhecida. E importante não esquecer que tudo isto se passa muito antes, uns trinta anos, da confeção do códice de que tratamos.

Os mestres europeus, todos portugueses, chamados à liça pelo impetuoso Padre Caetano, foram o P. João Vaz Barradas e Morato, mestre de capela da Igreja paroquial de $\mathbf{S}$. Nicolau e depois professor de música na. Sé de Lisboa; o Padre João da Silva Morais, mestre de capela da Catedral de Lisboa; o Padre Inácio Antônio Celestino, mestre da Catedral de Evora e respectiva claustra; o Padre Mateus da Costa Pereira e Abreu, mestre da Sé de Coimbra; o Padre Manuel Martins Serrano, mestre da Sé de Portoalegre; o Padre, Domingos Gomes Couto, mestre da Sé de Elvas e ainda Gregório de Sousa e Gouveia que tinha sido mestre da capela da Santa Casa da Misericórdia da Bahia e que era morador em Santo Amaro e vivera na Vila da Cachoeira. 
A entrada deste último na controvérsia, veio a propósito de certa dúvida que consistia na dificuldade que se reconhecia em afinar alguns instrumentos de corda, como as violas e violoncelos, com as vozes. Quem conheça a história das variações da frequência do diapasão, reconhecerá a legitimidade do problema que se punha nas primeiras décadas do século XVII na cidade brasileira da Bahia. Bastará lembrar que só em 1885 foi aceito universalmente a altura do diapasão com 870 vibrações, o LA 3, chamado o La normal.

Quanto ao primeiro assunto que provocou o Diálogo Apologético, consistia no seguinte. Como é sabido, até fins do século XVII as quintas eram rigorosamente naturais, de modo que 0 construtor dos cravos obtinha uma escala de doze sons cujos intervalos eram desiguais e que interditava a utilização de tonalidades com mais de três sustenidos ou mais de dois bemois. Mas, por outro lado, a teoria, neste caso, muito bem exposta pelo $\mathbf{P}$. Mestre da Capela da Sé de Evora, dizia que todos os signos da oitava diatônica podiam ser sustenidos e bemois, sem que se faltasse à lei da escala que deveria ter 5 sons e dois meios tons. Simplesmente, na prática, ninguem fazia uso do sistema. A questão não era de lana caprina, era problema de ordem técnica que exigia solução na ordem prática. E o certo é que, nas primeiras décadas do século XVIII, alguns construtores resolveram falsificar ligeiramente certos intervalos de quinta, esforçando-se por obter intervalos rigorosamente iguais entre os dozes meios sons da escala. Este compromisso permitiu que todas as tonalidades pudessem ser tocadas. Desta solução nasceu a possibilidade dada a João Sebastião Bach para escrever o Cravo Bem Temperado com os vinte e quatro prelúdios, onze dos quais já tinham aparecido em 1720 no Klavierbüchlein de Wilhelm Friedemann Bach, o seu filho maior. Desta maneira, o prelúdio impôs a tonalidade e a fuga explorou-a.

Claro que não temos que nos admirar que estes trabalhos fossem desconhecidos no Brasil em 1738, ano da controvérsia, tanto mais que o Cravo bem Temperado, terminado em 1722, não foi publicado em vida do seu autor que faleceu em 1750 .

Como expressão de cultura européia no domínio da música, o trabalho do P. Caetano de Melo de Jesús, é simplesmente surpreendente. Com efeito, o acervo de conhecimentos históricos e teóricos concernentes à arte musical, é largamente abonado por vasta bibliografia denunciando variada leitura das mais autorizadas fontes na matéria. E a pergunta a fazer será esta: Como teria sido possivel, na cidade da Bahia, nas primeiras décadas do século XVIII, elaborar sobre teoria musical um trabalho tão extenso, tão profundo e tão ligado às raizes da música européia? 
Se, como pensou Ernesto Vieira, o Padre Caetano se serviu na primeira parte da Musurgia universalis, sive ars magna consoni et dissoni, do jesuita Athanasius Kircher (1650), podendo, por ele, citar Zarlino, Glareano, Boécio ou Guido d'Arezzo, o mesmo se não pode dizer quando cita os teóricos portugueses ou espanhois, como o P. Manuel Nunes da Silva, autor da Arte Minima, Lisboa, 1704; João Alvares Frovo, autor dos Discursos sobre a Perfeição do Diathesaron, Lisboa, 1662; Pedro Thalesio, autor da Arte de Canto Chão, Coimbra, 1618 e 1628; Antônio Fernandes, autor da Arte de Música de Canto D'Orgam e Canto Cham..., Lisboa, 1626; Mathias de Souza Villa-Lobos, autor da Arte de Canto Cham, Coimbra, 1688; Pietro Cerone, autor do El Melopeo y Maestro, Nápoles, 1613; Andrés Lorente, autor do El Porqué de la Música, Alcalá, 1672; Francisco Salinas, autor de De Música Libri VII, Salamanca, 1572; Pablo Nasarre, autor da Escuela Música según la Práctica moderna, Saragoza, 1723 e 1724 (dois volumes); Francisco Corrêa de Araujo, autor de La Facultad orgánica, Alcalá de Henares, 1626; Gonzalo Martínez de Bizcargui, autor de Arte de Canto Llano y Contrapunto, Burgos, 1543, e muitos outros, como Guilherme de Podio (Despuig), Valência, 1495 e Francisco de Tovar, Livro de Música Práctica, Barcelona, 1510 , etc. .

Não creio que o P. Caetano de Melo de Jesus tivesse tido à mão todas as obras que cita nas margens dos dois grossos volumes que escreveu; e não creio porque algumas dessas obras são peças raras dispersas por bibliotecas e arquivos. Mas a verdade é que mostra conhecimento directo das teorias de cada um, o que, antes de mais nada, significa uma real transplantação da cultura ocidental para o Brasil levada pelos colonizadores de Portugal. O trabalho do mestre da Capela da Catedral da Bahía prova-o exuberantemente e sem sombra de qualquer dúvida.

Compulsando os dois volumes manuscritos, fica-nos a certeza de que vieram para o continente com o fim de serem impressos. Apadrinhou o P. Caetano, o Senhor Bernardino Marques de Almeyda e Arnizall, Cavalleyro profano na Ordem de Christo, Familliar do Sancto Officio dos da Inquisição da Côrte de Lisboa; Capitão de Infantaria de auxiliar da Guarnição desta Praça da Bahia; Cidadão da Ordem dos Vereadores della; Bacharel formado, e Mestre em artes em Philosophia; Academico de numero, $e$ $V$. Secreatrio da Academia Brasilica dos Renascidos, de quem o autor se confessa reverente Capelão. Não averiguei quem foi este personagem carregado de títulos, mas afigura-se-me que tenha sido pessoa de raro prestígio no meio social bahiano.

Porque razão a obra ficou manuscrita? Podem levantar-se várias conjecturas mais ou menos aceitáveis, mas possivelmente, 
nenhuma será a verdadeira. O fato que interessa à cultura do Brasil é a existência dos Códices na Biblioteca de Evora e cujo conteudo não tem paralelo no historial da nação irmã. Só será de lamentar que não existam o terceiro e o quarto volume anunciado, mas, apesar disso, o que existe é trabalho que honra um autor e o meio cultural onde se desenvolveu, neste caso, a cidade da Bahia, que desde 1549 a 1763 foi o centro administrativo e dinâmico do Brasil.

José Augusto Alegria.

Até aqui as autorizadas palavras do ilustre Prelado, quem redescobriu para nós tamanha obra. O que devemos admirar imediatamente, é a incrivel migração não apenas humana e material, para as Américas, mas tambem a dos produtos espirituais. O mais grave erro do século passado e de boa parte do atual consistiu precisamente em crer que os meios culturais, mormente os dos séculos XVII e XVIII, estivessem na nossa América carentes de informação contemporânea nos campos da poesia, literatura e artes e que nos acontecimentos solenes e festivos houvesse havido apenas reflexo e imitação ostensiva do que se realizava nas respetivas metrópoles. Grave erro. Os compositores de Minas Gerais, para citar um exemplo, se achavam inteiramente a par do que acontecia na Europa, porque recebiam, por iniciativa própria, por espírito de superação, tudo quanto se produziu na Europa, apenas com uma diferença de poucos anos. Isto não foi somente um sintoma dos mulatos mineiros. Foi atitude proverbial em toda a América Latina. Quanto mais isolado se achava o homem, mais precisava de se nutrir de elementos espirituais. O cordão umbilical continuava alimentando aos que se sentiam ligados às patrias madres. O Don Quijote de la Mancha foi achado na sua primeira edição em Lima, apesar da prohibição dos chamados Libros de Caballería. Em 1553 já tinha chegado à Catedral de Cuzco o primeiro Livro de 16 Missas de Morales, publicado em Roma em 1544. A Quito chegaram bem cedo os Motetes de Francisco Guerrero, publicados em Veneza em 1570. Insistimos que eram e continuam sendo regiões de dificil acesso pelo íngrime das alturas andinas. Em Vila Rica, capital das Minas Gerais, formou-se uma biblioteca de quase 700 volumes de obras de arte, segundo nos revelou o insigne historiador Dr. Geraldo Dutra de Moraes, tendo tambem ele comprovado a remessa, de Lisboa, respondendo a requerimentos provindo de Minas Gerais, de obras de Byrd, Palestrina, Orlando de Lasso, Purcell, Pergolesi, Händel, Lully, Scarlatti, Rameau, Frescobaldi, Monteverdi, Haydn e Mozart. Outros caixotes iam sendo remetidos sem especificação do seu conteudo ou com a documentação hoje perdida. Aconteceu o mesmo processo de nutrição musical desde a Fundação da Província do Paraguay, pela Com- 
panhia de Jesus, em 1608, até a sua expulsão em 1767, enchendo as prateleiras dos Povos de Missões com inúmeras obras européias e o salão de música com profusão de instrumentos. Certamente, o índio não foi criador, pois chegava apenas a excelentes interpretações, mas em Minas Gerais, o mulatismo musical aproximou-se muito perto das expressões mais elevadas da arte musical do Velho Mundo.

As primeiras edições das obras de grandes teóricos europeus, e particularmente dos espanhois e portugueses foram localizadas por mim em numerosos conventos e mosteiros do Brasil e da Argentina, para não falar da Colômbia, do México, do Perú. Menciono naturalmente, os insignificantes restos do que foi enviado anos atrás para a América Latina. Comprei nos antiquários de São Paụlo vários livros de teóricos portugueses, alguns destes de canto-chão, e não devemos esquecer que na Biblioteca Nacional do Rio de Janeiro se acham a primeira e a segunda edição do Pedro Thalésio, e um Livro de Orações com Cantochão, do ano 1490, com mais de 600 páginas, no qual se encontra incluido integramente o Tratado de Johannes de Garlandia: In nomine domini incipit introductio musicae planae et etiam mensurabilis secundum magistrum Johannem de Garlandia musicae sapientissimum rectorem.

No Museu da Arquidiocese de Mariana ainda se encontram algumas preciosidades, como o Livro de Canto Gregoriano, pertencente à liturgia dos abades cistercienses, e um Passio Domini de Francisci Ludovici, em 4 grandes volumes, aparte dum Graduale Romanum, livro manuscrito de consideráveis proporçōes. Em toda a América Latina há uma flagrante demonstração das preocupações que tiveram os Superiores dos Conventos e Mosteiros, ou diretamente os Provinciais, assim como os Cabidos eclesiásticos das Catedrais para se munir dos melhores elementos da arte dos sons. Já por um princípio estabelecido ao largo de mais de dois séculos, quando o clero seguia ordens superiores para se transferir às possessões ultramarinas, conduzia consigo os melhores elementos do serviço litúrgico, geralmente como bagagem pessoal, para estar bem provido de todo o necessário. Tal foi tambem a conduta do mestre de capela, do organista, do chantre. Tambem devemos levar em conta que na Bahia, logo após a expulsão dos Jesuitas em 1759, a biblioteca ficou a mercê do clero secular, porque a sua Igreja foi elevada a Catedral, pouco antes de lançar em forma definitiva o Padre Caetano de Melo de Jesus a sua obra em dois volumes, embora trabalhasse nela durante vários decênios. Ele teria acesso às outras bibliotecas, assim como por exemplo a de São Bento, tradicionalmente muito nutrida de obras teóricas e práticas, sempre que neste mosteiro se houvesse salvado parte ou toda a biblioteca após a conquista da capital pelos holandeses e a reconquista aos poucos anos pela frota combinada luso-espanhola. 
Todo era possivel neste novo mundo no qual, os mesmos homens que o povoavam, tinham postos as suas grandes esperanças, pois sabia-se que dificilmente voltariam à terra que os viu nascer. Lembro-me de Cervantes, que em idade provecta, ainda aspirava, com a sua portentosa obra nas costas, transladar-se definitivamente às Indias Occidentais, onde seguramente teria continuado a sua obra de autor imortal. Não me estranha, portanto, que o Padre Caetano tivesse tido à mão quase todas, ou todas as obras que ele comenta não apenas de passagem, para aparentar, como fazem tantos historiadores, uma grande experiência bibliográfica, senão para citar profusamente, com conhecimento de causa, o ponto de vista dos seus colegas.

Muito interessante, como iniciativa e ao mesmo tempo como atitude valerosa, foi a decisão do Padre Caetano de submeter a sua obra aos pareceres de colegas respeitáveis. Poderiam ter sido alguns amigos indulgentes, o Padre esperando-se deles talvez uma apreciação do esforço realizado, mas não do conteudo. Sem embargo, o Padre Caetano não especulou com considerações benevolentes nem as teria achado, devido aos pontos de vista dele, que deviam forçosamente encontrar uma certa resistência em mentalidades menos curiosas, menos desenvolvidas às dele e talvez mesmo, em alguns casos, retrógadas. Já temos visto na comunicação do Cônego Alegria os nomes das personalidades às quais ele remeteu o seu trabalho no Brasil e em Portugal, "na América e na Europa", como ele destaca. As censuras recebidas logo do estudo pelos seus colegas deram lugar a impugnações e até a uma queixa do autor. Naturalmente, tais diálogos, achando-se muito distante dos colegas consultados, tanto no Brasil como ainda mais com respeito ao longínquo Portugal, devem ser minuciosamente estudados para se chegar a uma conclusão crítica objetiva. Neste ir e vir dos volumes, passaram-se os anos e uma vez recebidas todas as Censuras, foram incluidas com as respostas na segunda parte da obra, que foi o momento, cronologicamente falando, em que ele resolveu dar forma definitiva ao seu portentoso trabalho.

A abundância de exemplificações musicais e a terminologia nada comum, fizeram particularmente dificil para o copista de as por a limpo, pois é de imaginar que não foi ó nosso mestre de capela que ocupou-se desta tarefa e sim, um calígrafo de primorosa letra e bom ponto para os trechos de notação. Numa das páginas da obra, vi uma pequena correção feita com mão de pessoa idosa que explica, sem dúvida, que o trabalho foi encomendado a alguem do meio bahiano, sob vigilância e revisão do Padre Caetano. Parece-me, sem ter siquer a menor informação sobre a vida e atividades deste mestre de capela, que culminou a sua carreira na Catedral da Bahia e que não chegou a completar os dois volumes seguintes, por ele anunciados. Os teria já 
muito elaborados, porem, sem os concluir quando lhe surpreendeu a morte.

Os dois primeiros volumes foram dedicados a personagem para nós tambem desconhecida, mas é curioso que entre os diversos títulos que ostenta, esteja figurando tambem o de Veneravel Secretário da Academia Brasílica dos Renascidos. Convem explicar ao leitor as curiosas circunstâncias que guardam relação direta com o Recitativo e Aria de autor anônimo, composta na Bahia em 1759 e dedicada a Joseph Mascarenhas Pacheco Pereira Coelho de Mello, chegado à Bahia em agosto de 1758, com funções específicas encomendadas pelo Conselho Ultramarino, como a criação dos Tribunais do Conselho de Estado e Guerra, e a da Mesa de Consciência, bem como instruções secretas para agir contra os jesuitas. Não tendo dado cumprimento a estas últimas, lhe valeram meses após o seu estabelecimento na capital brasileira, prisão por vinte anos.

Seu nome está intimamente ligado à Academia Brasílica dos Renascidos, que reviveu aquela dos Esquecidos, cuja última sessão fora a 4 de julho de 1725 . Foi de vida efêmera mas intensa, tendo tido por membro correspondente o poeta mineiro Cláudio Manoel da Costa. Fundada a nova Academia sob os auspícios de Mascarenhas a 6 de junho de 1759 , reuniram-se 40 Acadêmicos no magnífico salão do Convento dos Carmelitas Descalços, luxuosamente ornamentado, ficando "o côro de música de fronte a uma porta de entrada principal". Alberto Lamego, feliz possuidor do Recitativo e Aria e vasta documentação sobre a Academia, fez uso dos documentos pertencentes a arquivos portugueses e nos proporciona, com referência a esta fez detalhada descrição. Disse-nos o autor do trabalho, que logo após a primeira Assembléia da Academia, Mascarenhas caiu gravemente enfermo, tendo sido rezadas missas em ação de graças pelo seu restabelecimento. A Academia the ofereceu uma festa íntima aos 2 de julho, a escassas semanas do ato inaugural e dedicou-lhe um Recitativo e Aria, executado por boa orquestra, sem mencionar-se quem esteve encarregado da voz humana. Deve ter sido fora de dúvida homem cantando em falsete, pois não se teria admitido, nem era hábito, acudir à voz duma mulher.

Se ao Secretário da Academia, Bernardino Marques de Almeyda e Arnissau, foi dedicada a Escola de Canto e Orgão, no mesmo ano da fundação da Academia Brasílica dos Renascidos, cabe perguntar-se se entre os quarenta membros da novel instituição não tomaria parte o Padre Caetano de Melo de Jesus. Em todo caso, animado pela presença e atividade conjuntd dum organismo acadêmico, a obra foi devidamente encaminhada. Embora tivesse a Bahia naqueles anos di- 
versos mestres-de-capela que seriam ao mesmo tempo tambem mestres-compositores, poderia existir a possibilidade de ter sido talvez o próprio mestre de capela, Padre Caetano, o compositor do Recitativo e Aria, com o seu bajulante texto hiperbólico, próprio do Barroco.

Faz bastante anos, o ilustre Cônego José Augusto Alegria exhumou da mesma Biblioteca Pública de Evora, onde se acha guardada a obra do Padre-Mestre, um curioso Dicionário Biográfico de Músicos Portugueses, que fazia tambem inclusão dos músicos destacados do Brasil que pertenciam, como todos os homens e todo o território, juridicamente ao Reino. Esta obra, aparecida primeiro na Revista Ocidente (Lisboa, 1944-45), com Prefácio e Notas do Cônego evorense e aparecida logo em Separata, traz uma breve referência, em página 19, ao mestre-de-capela bahiano:

"Caetano de Melo natural da Cidade da Bahia. Compos diversas obras a 4, e mais vozes, Compos huma Arte de Canto de Orgão em Dialogo, e hum tratado dos tons, cujas obras existem na Bahia, e Pernambuco."

Nada nos diz o autor da obra, José Mazza, músico de origem italiana estabelecido em Portugal, sobre o seu cargo na Catedral. A informação que lhe coube reunir é escassíssima, mas nos revela ao menos, que foi compositor.

Como quer que seja, pois nos estamos movendo em hipóteses, a coincidência da data entre a fundação da Academia Brasílica dos Renascidos e a versão definitiva da notavel obra teórica é mais que significativa e ressalta a existência dum pequeno empório de atividade musical erudita, que convem aprofundar, na maior brevidade possivel. Desenvolveu-se paralelamente com a erudição espalhada por todos os povoados de Minas Gerais e foi intensificada, na Bahia e outros pontos do imenso país, com o ouro vindo das Gerais.

O leitor perguntará sem dúvida pelo curso que deveria tomar o estudo pormenorizado da obra. Quando cheguei a Lisboa, após breve permanência em Evora, apresentei-me perante as autoridades do Instituto de Altos Estudos, do qual fui, em 1961-62 hóspede, explicando o caso e assinalando a importância da obra. Solicitei que esta fosse microfilmada, para eu iniciar o estudo detalhado dos dois Códices, e escrever um prólogo extenso com estudos comparativos sobre as diversas controversias suscitadas, seguido da edição facsimilar dos volumes, previstos ainda de notas. Pedi inclusive a autorização ao Cônego Alegria, pois poderia ele ter tido interesse de se dedicar ao assunto. Concedeu-me este privilégio e encaminhado perante o Instituto de referência, a Direção dos Assuntos culturais do Ministério da Educação e Cultura respondeu ao Cônego textualmente: 
"Tenho a honra de informar V. Exa de que o director do Instituto Interamericano de Musicologia de Montevideu solicitou a oferta da microfilmagem dos manuscritos da "Escola de Canto e Orgão" da autoria de Caetano de Melo de Jesus, existente na Biblioteca de Évora, a fim de proceder à sua edição facsimilar no Brasil.

Dado ser uma obra de interesse nacional deveria essa obra ser editada em Portugal.

Assim, solicito a V. Exa se digne informar-me da possibilidade de orientar a edição dos referidos manuscritos...".

Foi intenção minha propor a edição destes volumes às autoridades brasileiras, uma vez concluidos os estudos. Parecia-me, e continuo pensando da mesma maneira, que correspondia ao Brasil honrar a memória dum filho ilustre, desconhecido ainda no volume da sua personalidade, para se desta forma render homenagem a mais um valor que se achava esquecido, "submerso naquele vazio colonial", segundo as tétricas afirmaçōes de um chamado historiador da música erudita no Brasil, amador, sem antecedentes de pesquisa histórica alguma, que negou a cultura musical portuguesa ter atravessado centúrias de sublime glória e ao mesmo tempo atribuiu incapacidade ao povo brasileiro de assmiliar a preciosa semente, por ele ignorada, que foi colocada nesta terra conduzindo a um desenvolvimento, dentro de período colonial, a alturas não imaginadas,

"que carecia de música erudita pela falta de capacidade de a assimilar e tambem pela carência dos portugueses de a transmitir".

No dia de hoje pedi ao Reverendo Cônego Alegria que queira se incumbir do estudo da obra do Padre Caetano, para o qual possui sobrada capacidade, porque tendo ficado sem a possibilidade de receber um microfilme dos dois Códices, o estudo deles se faz impossivel. Não é de importância decisiva o lugar da publicação, se no Brasil ou em Portugal. Essencial é o estudo e a edição facsimilar do que o Padre Caetano nos tem legado como demonstração da sua grande capacidade de teórico e prático progressista e como testemunha duma época que honrou as tradições musicais lusitanas e soube colocar a semente em solo virgem onde frutificou com renovada seiva, como no caso do Padre Caetano de Melo de Jesus e de muitos outros. 


\begin{abstract}
ANEXO I
Aspeto detalhado dos dois Códices da autoria do Padre Caetano de Melo de Jesus.
\end{abstract}

ESCOLA / DE / CANTO DE ORGÃO, / MUSICA PRACTICADA EM FORMA DE / DIALOGO ENTRE DISCIPULO, E MES- / TRE, DIVIDIDA EM QUATRO PARTES./

PARTE I. /

DA / MUSICA THEORICA / OU / METHODO DOUTRINAL, / QUE PRACTICA, E THEORICAMENTE, SEGUNDO OS MODER- / NOS, EXPLICA AOS PRINCIPIANTES OS PRINCIPAES PRECEY- / TOS DA ARTE./ AUCTHOR /

O M.R.P. CAETANO / DE MELLO DE JESUS, / SACERDOTE DO HABITO DE S. PEDRO, MES- / TRE DA CAPELLA DA CATHEDRAL DA BA- / HIA e NATURAL DO MESMO / ARCEBISPADO. / ANNO DE / 1759./

[1 pág. titular, pp. 4: Dedicatória: Obra dedicada ao $\mathrm{Sr}$. Bernardino Marques de Almeyda e Arnissau, Cavalleyro profano da Ordem de Christo, Familliar do Sancto Officio dos da Inquisição da Côrte de Lisboa, Capitão de Infantaria de auxiliar da Guarnição desta Praça da Bahia, Cidadão da Ordem dos Vereadores della, Bacharel formado, e Mestre em artes, em Philosophia, Academico de numero, e V. Secretario da Academia Brasilica dos Renascidos.]

ESCOLA / DE / CANTO DE ORGÃO / MUSICA PRACTICADA EM FORMA DE DIA- / LOGO ENTRE DISCIPULO, E MESTRE, / DIVIDIDA EM QUATRO PARTES. /

[Em branco, pp. 2; Prologo ao Leytor, pp. 15; em branco pp. 2 sem numeração; texto pp. 564; em branco pp. 2; Index pp. 34 sem numeração; em branco pp. 6].

PARTE II. /

NUMERAL, OU ARITHMETICA / DA / THEORICA DOS INTERVALLOS, / CUYA ORIGEM PROPORÇOENS, E PROPORCIO- / NALIDADES, PRACTICA, E THEORICAMENTE SE / EXPLICA AOS PRINCIPIANTES POR SEO / AUCTHOR / O M.R.P. CAETANO / DE MELLO DE JESUS, / SACERDOTE DO HABITO DE S. PEDRO, MES- / TRE DA CAPELLA DA CATHEDRAL DA BA- / HIA, E NATURAL DO

MESMO / ARCEBISPADO / ANNO / DE 1760./

1 pág. titular; em branco, 2 pp.; texto, pp. 630; Censuras dos MM.RR.PP.MM./

Animo da America, como da Europa, que respon- / dêrão á Dúvida, que neste Discurso / Apologêtico se contêm. /

Censuras da America. / 
Censuras do M.R.P. Ignacio Ribeyro / Noyo, Mestre da Villa do Recife / em Pernambuco. 28 de Outubro de 1734. [pp. 531-32].

Censura do M.R.P. Ignacio Ribeyro Pimenta, Mestre da Capella da Cathedral de Olinda. 6 de Novembro de 1734. [pp. 532-33].

Censura do M.R. Arcediago da Cathedral de Olinda, Manuel da Costa Rego. 9 de Novembro de 1734. p. 533.

Censura do M.R.P. Antonio Nunes da Siqueira, Mestre da Capella da Cathedral do Rio de Janeiro. 2 de Julho de 1735. [pp. 534-38, com exemplos musicais].

Censuras da Europa [p. 539, p. $540 \mathrm{em}$ branco]

Censura do M.R.P. Ignacio Antonio Celestino, Mestre da Capella do Claustro de Evora. Março 6 de 1738. [pp. 541-44].

Censura do M.R.P. João Barradas, Mestre da Capella da Parroquial Igreja de $S$. Nicolas de Lisboa Occidental, e da Cadeira de Musica da Sé depois Basilica de $S^{a} M^{a}$ [pp. 545-559].

Censuras do D.or Joseph Ferreyra Cordovil (e impugnação) [pp. 559-65].

Censuras do M.R.P. João da Sylva Moraes, Mestre da Capella da Santa Igreja de Lisboa (da Sé de Lisboa Oriental). 24 de Abril de 1738. [Ocupa a p. 566, seguindo uma "Queija do Aucthor" em pp. 566-67].

Censuras do M.R.P. Mattheos da Costa Pereyra e Abrés, Mestre da Capella da Se de Coimbra. pp. 567-68. Segue uma impugnação do Aucthor [pp. 568-70].

Censuras do M.R.P. Domingos Gomes de Couto, Mestre da Capella da Cathedral de Elvaz, sem data, como as anteriores. [Censura: pp. 570-72; Impugnação do Aucthor: pp. 572-75]

Censura do M.R.P. Manuel Martins Serrano, M.e da Capella da Sé de Portoallegre. [Censura: pp. 575-79; Impugnação do Aucthor: pp. 579-83. p. $584 \mathrm{em}$ branco].

Duvida de Gregorio de Souza e Gouveas, Mestre que foi da Capella da Sancta Casa de Misericordia desta Cidade, e resposta do Aucthor. [pp. 585-87; p. 596 em branco. Seguem Index com pp. 42 e 3 em branco].

Mapas fora de texto (citamos apenas Arvore da Divisão, Taboa das Claves duras e brandes, etc.), e numerosas exemplificações musicais. 


\section{ANEXO II \\ Bibliografia do Autor (essencial).}

La Música en Minas Gerais. Un Informe preliminar, in "oBletín Latino-Americano de Música", Tomo VI, Rio de Janeiro, 1946, pp. 409-494., il.

Archivo de Música Religiosa de la "Capitania Geral das Minas Gerais", Siglo XVIII. Hallazgo, Restauración y Prólogo de ... (Três partituras: Antiphona de Nossa Senhora (Salve Regina), de José Joaquim Emerico Lôbo de Mesquita, Arrail do Tejuco, 1787; Hymno (Maria Mater Gratiae), de Marcos Coelho Netto, Vila Rica, 1789; Novena de Nossa Senhora do Pilar, de Francisco Gomes da Rocha, Villa Rica, 1789. Ed. Departamento de Musicología, Universidad Nacional de Cuyo, Mendoza, Argentina, 1951.

A Organização Musical durante o Período colonial brasileiro, in "V Colóquio Internacional de Estudos Luso-brasileiros", Coimbra, 1966.

Os Compositores na Capitania Geral das Minas Gerais. I. José Joaquim Emerico Lobo de Mesquita, in Revista "Estudos Históricos" N.os 3-4 da Faculdade de Filosofia, Ciências e Letras de Marília, Estado de São Paulo, 1965.

A Música na Vila Real de Sabará, in Revista "Estudos Históricos" N.o 5, Dezembro de 1966, da Faculdade de Filosofia, Ciências e Letras de Marília, Estado de São Paulo, 1966

Os Irmãos Músicos da Irmandade de São José dos Homens Pardos de Vila Rica, in "Anuário" Vol. IV, Inter-American Institute for Musical Research, Tulane University, New Orleans, La., 1969 (com diferente material documental acréscimos).

La Música en Villa-Rica. As Arrematações de Música do Senado da Câmara. (Nómina de cantores, inst:umentistas e regentes), in "Revista Musical Chilena", Nis 102-03, Santiago de Chile, 1967-68).

As Danças coletivas Públicas no Período colonial brasileiro e as Danças das Corporações de Ofícios em Minas Gerais, in Revista "Barroco", vol. I, Belo Horizonte, 1969.

Obras de Autores Mineiros restauradas, postas em Partitura, e Notação moderna.

Lobo de Mesquita, José Joaquim

Missa No 1, em mi bemol

Missa N.o 2, em fá 
Te Deum

Ladainha

Offertório de Nossa Senhora

Antífona de Nossa Senhora (Salve Regina)

Officium Defunctorum (N.o 1)

Domenica Palmarum

Quatro Tractus de Sábado Sancto.

Gomes da Rocha, Francisco

Novena de Nossa Senhora do Pilar

Ad Matutinum. Invitatorium et Hymnus de Spiritus Domini.

Parreiras Neves, Ignácio

Credo.

Coelho Netto, Marcos

Hymno (Maria Mater Gratiae).

Dias de Oliveira, Manoel

Tractus e Bradados da "Sexta-feira Santa".

Autor Anônimo

Oito Motetos para duplo côro misto para Sexta-feira da

Semana Santa, com acompanhamento de órgão.

Autor Anônimo

Quatro Antífonas em honra a São Francisco.

\section{Discografia}

Mestres do Barroco Mineiro (século XVIII). 2 discos: Lobo de Mesquita: Missa em mi bemol e Antífona de Nossa Senhora; Parreiras Neves: Credo; Coelho Netto: Hymno; Gomes da Rocha: Novena de Nossa Senhora do Pilar. Discos Festa, LDR 5005-06. Solistas, Associação de Canto Coral do Rio de Janeiro (Regente: Cleofe Person de Mattos) e Orquestra Sinfônica Brasileira, Regente: Edoardo de Guarnieri.

Offertório de Nossa Senhora, Lobo de Mesquita. Discos Chantecler, Stereo. CMC 1030, Orquestra de Câmara de São Paulo, Regente: Olivier Toni.

Quatro Tractus para Sábado da Semana Santa, Lobo de Mesquita. Discos Chantecler, CMG-1042. Grupo Coral do Instituto Cultural Italo-Brasileiro, Regente: Walter Lourenção.

Ad Matutinum. Invitatorio e Hino de Espirito Santo, de Francisco Gomes da Rocha; e Antifona (Salve Regina) de José Joaquim Emerico Lobo de Mesquita, Discos Qualiton, Buenos Aires, SQI-4038 Stereo. Apareció com o título "Música Colonial Latinoamericana". 